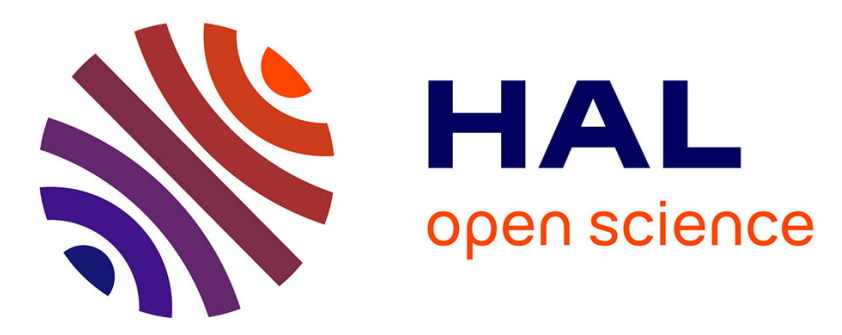

\title{
Optimization of electrical energy storage system sizing for an accurate energy management in an aircraft
}

Pierre Saenger, Nathalie Devillers, Karine Deschinkel, Marie-Cécile Péra, Raphael Couturier, Frédéric Gustin

\section{- To cite this version:}

Pierre Saenger, Nathalie Devillers, Karine Deschinkel, Marie-Cécile Péra, Raphael Couturier, et al.. Optimization of electrical energy storage system sizing for an accurate energy management in an aircraft. IEEE Transactions on Vehicular Technology, 2017, 66 (7), pp.5572 - 5583. hal-02129856

\section{HAL Id: hal-02129856 \\ https://hal.science/hal-02129856}

Submitted on 15 May 2019

HAL is a multi-disciplinary open access archive for the deposit and dissemination of scientific research documents, whether they are published or not. The documents may come from teaching and research institutions in France or abroad, or from public or private research centers.
L'archive ouverte pluridisciplinaire HAL, est destinée au dépôt et à la diffusion de documents scientifiques de niveau recherche, publiés ou non, émanant des établissements d'enseignement et de recherche français ou étrangers, des laboratoires publics ou privés. 


\title{
Optimization of electrical energy storage system sizing for an accurate energy management in an aircraft
}

\author{
P. Saenger, N. Devillers, K. Deschinkel, M.C. Péra, R. Couturier, F. Gustin
}

\begin{abstract}
The development of More Electrical Aircrafts leads to the adaptation of their electrical architecture and their capacity of power generation and storage. Therefore, generation and storage systems must be well-sized to match their energetic performances versus the vehicle requirements. This paper deals with the optimal sizing of storage systems (secondary batteries and supercapacitors) for an aircraft. In this particular application, the global weight of the whole storage system must be minimized. An optimal sizing tool has been developed to reach this objective by acting on setting parameters which are the cutoff frequency of the low-pass filter (to share out the mission profile between storage systems according to an energy management based on a frequency approach), the discharge ratio for storage components (in relation with their technological limits and the electrical network specifications) and temperature (which can be seen as an environmental constraint as well). The optimization results, obtained with the simulated annealing method implemented in Matlab ${ }^{\circledR}$, are presented and assessed throughout the whole temperature range. Finally, the impact of setting parameters on the global storage system weight is studied and an adaptation of the energy management strategy is presented to take into account the temperature influence on battery performances.
\end{abstract}

Index Terms- Electrical Energy Storage System; supercapacitor; secondary battery; sizing; optimization; energy management; embedded electrical network

\section{INTRODUCTION}

$\mathbf{I}_{\mathrm{p}}^{\mathrm{n}}$ More Electric Aircraft (MEA), the embedded electrical power is higher and higher due to the electrification of auxiliary systems [1]. To provide the growing energetic requirements, Electrical Energy Storage Systems (EESS) are

Paper submitted for review on March, 7th 2016

This work was supported in part by Région Franche-Comté - France.

Pierre Saenger, Karine Deschinkel and Raphaël Couturier are within the department of computer science for complex systems from the FEMTO-ST Institute / University of Bourgogne Franche-Comte, 90010 BELFORT France (e-mail: pierre.saenger@femto-st.fr, karine.deschinkel@univfcomte.fr, raphael.couturier@univ-fcomte.fr).

Nathalie Devillers is within the department of electrical engineering from the FEMTO-ST Institute / FEMTO-Engineering Center, 90010 BELFORT France (e-mail: nathalie.devillers@femto-st.fr).

Marie-Cécile Péra and Frédéric Gustin are within the department of electrical engineering from the FEMTO-ST Institute / University of Bourgogne Franche-Comte, 90010 BELFORT - France (e-mail: mariececile.pera@univ-fcomte.fr, frederic.gustin@univ-fcomte.fr). integrated in new electrical architectures in complement to usual generators of electrical energy. In some operation modes, such as engine start, taxiing time or electrical emergency back-up, EESS can be the only available sources in the aircraft. Therefore, they provide all or some of the required energy, depending on the hybridization rate and on the mission profile. Moreover, EESS can also be useful to improve the reliability, the stability and the quality of the electrical network. Thus, they contribute to the on-board energy management.

In our aeronautic application, the embedded EESS are supercapacitors and secondary batteries because of their complementary characteristics, which are summed up in a first part. Then, the considered electrical system, including EESS, is presented. In the third part, a method is detailed for the optimal sizing of EESS. After a presentation of the sizing results, their relevance is assessed and the influence of setting parameters is analyzed in the last part.

In literature [2], [3], [4], authors suggest sizing tools for supercapacitors or secondary batteries, where only one storage system is sized at a time and with one pre-chosen cell. In a previous work [5], a tool was developed to size both EESS in parallel by choosing the appropriate cell among a library and by acting on the dispatching of the energetic requirements between storage systems, through the cut-off frequency of a low-pass filter, used for the energy management.

In this paper, the previous sizing method (developed in [5]) is improved with an optimization algorithm. The aim of this updated sizing tool is to reduce the global storage system weight, by taking into account several constraints (environmental and electrical ones) and by adjusting some parameters, such as the discharge ratio of storage components, the ambient temperature and the cut-off frequency from energy management strategy.

\section{ENERGY STORAGE SYSTEMS IN AIRCRAFT}

Recent developments in electrical DC distribution, in power electronics and in storage systems are more and more implemented in aircrafts [1]. Thanks to the integration of Electrical Energy Storage Systems, the hybridization of power sources, the energy recovery and the electrical supply in specific flight phases become possible. They also improve the 
electrical system reliability. For instance, the Boeing 787 was the first aircraft to embed a Lithium-ion battery. Other studies concern the implementation in some aircrafts of EESS, such as Lithium-ion battery [6] and supercapacitor bank [7].

Our aeronautic application needs to embed energy storage components, which can provide or recover electrical power. Two EESS: supercapacitors and Lithium-ion Polymer batteries, were chosen because they are complementary [8], [9]. First of all, their energetic performances (specific energy and power) complement one another, as seen usually in Ragone plots [10], [11]. For supercapacitor or Double-Layer Capacitor (DLC) systems, the specific energy is between 5 and $15 \mathrm{Wh} \cdot \mathrm{kg}^{-1}$ and the specific power is between 800 and 2,000 W. $\mathrm{kg}^{-1}$. As for Lithium-ion Polymer secondary battery systems, the specific energy is between $120-140 \mathrm{Wh}^{-\mathrm{kg}^{-1}}$ and the specific power is between $10-1,000 \mathrm{~W} \cdot \mathrm{kg}^{-1}$.

Moreover, supercapacitor and Lithium-ion Polymer battery are complementary on other characteristics, such as discharge time, life duration (number of cycles), energetic efficiency and auto-discharge rate. The discharge time for supercapacitors is rather low (about few seconds [10]) in comparison with other storage systems, such as Lithium batteries. Their discharge time is about several minutes or hours and depends on the discharge current-rate. The life duration of a Lithium battery is higher than the lifetime of Lead or Nickel batteries, but lower than the supercapacitor's one. Indeed, the number of cycles is around 1,500 for Lithium-ion Polymer batteries and between 100,000 and 500,000 for supercapacitors [9]. Both of these storage components have a good energetic efficiency, which is between 95 and $98 \%$ for a supercapacitor, and close to $100 \%$ for a Lithium-ion Polymer battery (because of the nonaqueous electrolyte). This kind of battery also has a low autodischarge rate, which is between 0.1 and $0.5 \%$ a day, whereas the supercapacitor auto-discharge rate is more important and about $5 \%$ a day [11].

A graphical comparison of these storage systems is suggested in [5] through a spider web diagram and a five-level scale, where the fifth level indicates the best performance. This diagram is given in Fig. 1 and is completed with a seventh criterion, which is EESS behavior according to temperature. In fact, characterization results, presented in [12] and [13], show that supercapacitors and Lithium-ion Polymer batteries can be associated because their performances are complementary, and particularly at low temperature.

\section{THE ELECTRICAL POWER SYSTEM ABOARD THE AIRCRAFT}

In the next paragraphs, the embedded electrical power system, which is composed of DC bus, converters, loads and sources, and storage components in particular, is described. Then, the strategy to dispatch load requirements between available sources is explained.

\section{A. Electrical power system}

Generally, aircraft electrical systems include devices for the electrical energy generation, storage, conversion and

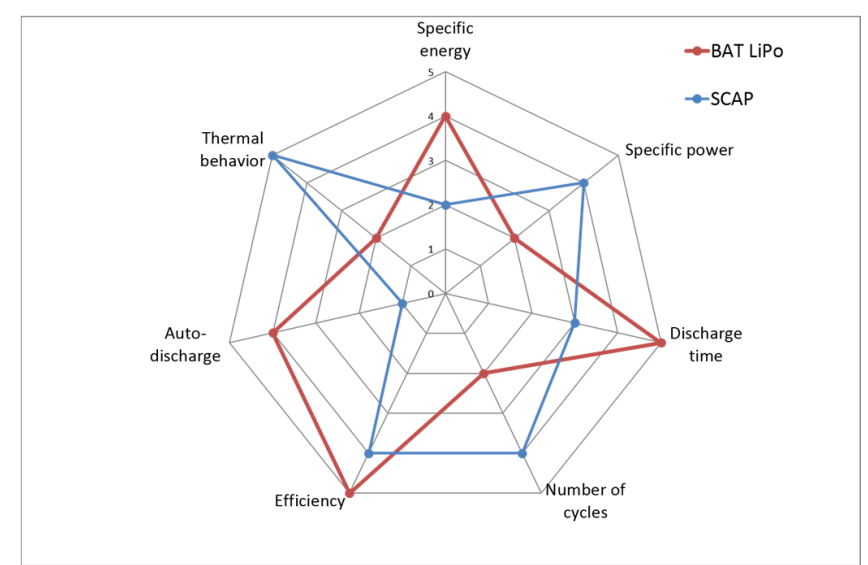

Fig. 1. Spider web diagram for comparison of supercapacitor (SCAP) and Li-ion polymer battery (BAT LiPo) characteristics

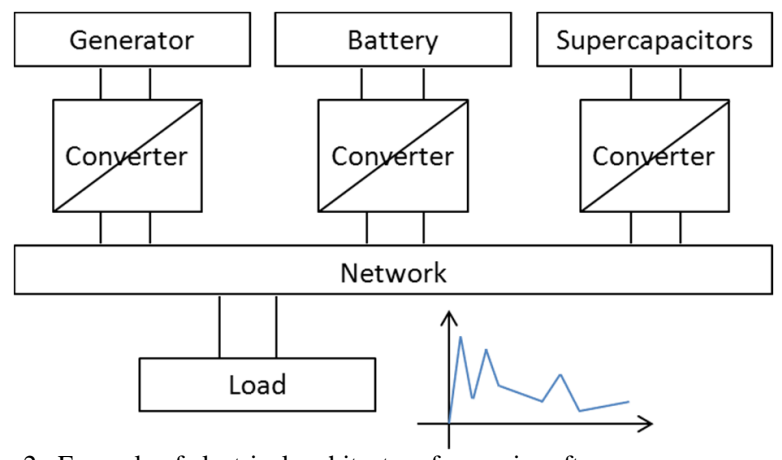

Fig. 2. Example of electrical architecture for an aircraft

distribution. The studied electrical power system is given in Fig. 2. It is composed of a main supply device: the generator, which provides the average electrical power. There are also storage systems, such as secondary batteries and supercapacitors. In our application, the EESS role is to contribute to meet all or some of the energetic requirements, depending on the availability of the main generator. These different sources (generator and storage systems) are connected to the network through converters. The advantages of this configuration are the voltage regulation (normative requirement according to standards [14]) and the current control of the different sources (mandatory for energy management).

In an aircraft, there are a lot of electrical consumers. The various load profiles are gathered together to give a global load profile, as commonly done in other applications [15], [16]. Among all the possible load profiles, a typical one is taken on for this study.

\section{B. Energy management}

The aim of the energy management is to control sources (generator and EESS) so that they are used at their nominal operating point and in order to avoid operation in unfavorable conditions, such as inconvenient cycling for batteries or high dynamic power contribution for generator.

The energy management, developed for our application [17], dispatches the load requirements to the three sources, while respecting their energetic performances and technical 


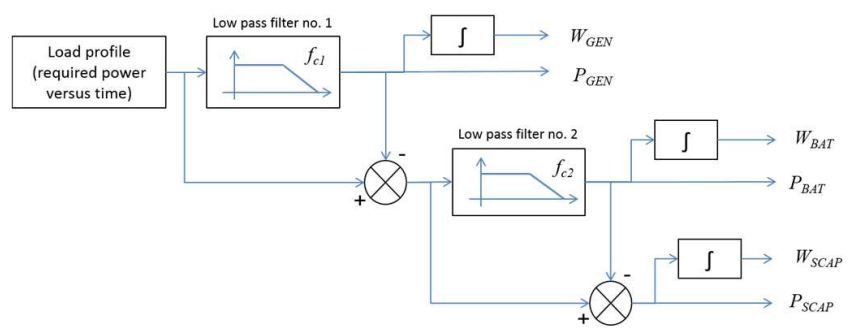

Fig. 3. Energy management based on a frequency approach adapted to three sources

characteristics. The supercapacitor system, usually considered as a power source, is able to provide or to recover power peaks, whereas the secondary battery system, considered as an energy source, is capable of providing power during a long time or transient power with a low dynamic rate. The generator supplies the average power with slow dynamics.

This energy management is based on a frequency approach. The energetic distribution is carried out with two low-pass filters (characterized by two cut-off frequencies $f_{C l}$ and $f_{C 2}$ ), as seen in Fig. 3. High frequency power is assigned to the supercapacitors (SCAP), low frequency power to the generator (GEN) and intermediate frequency power is assigned to the battery system (BAT). As this paper deals with the sizing of storage components, the power supplied by the generator is not taken into account. Actually, the mission profile considered for this study is the starting time, which is particularly critical for EESS operation because the generator has not started yet and cannot provide any continuous power [17]. Thus, the cut-off frequency of the second low-pass filter $f_{C 2}$ is one of the variables for the storage system sizing tool.

\section{OPTIMAL SIZING OF ELECTRICAL ENERGY STORAGE SYSTEMS}

EESS sizing consists in determining the suitable cell and combination of cells for each storage system so as to match their performances with the energetic requirements of the application. In an aircraft, the objective is to minimize the global system weight (and particularly the storage system weight). To reach this objective, a sizing tool has been developed and its algorithm is summed up in Fig. 4. The input data of this tool are detailed in a first part. They are

TABLE I

SUPERCAPACITOR CELL DATABASE FOR THE SYSTEM SIZING TOOL

\begin{tabular}{lcccccc}
\hline \hline \multirow{2}{*}{ Symbol } & Unit & \multicolumn{5}{c}{ Values $^{\mathrm{a}}$} \\
\hline$C_{\text {scap }}$ & {$[\mathrm{F}]$} & 650 & 1200 & 1500 & 2000 & 3000 \\
$R_{\text {scap }}$ & {$[\mathrm{m} \Omega]$} & 0.8 & 0.58 & 0.47 & 0.35 & 0.29 \\
$U_{\text {scap }}$ & {$[\mathrm{V}]$} & 2.7 & 2.7 & 2.7 & 2.7 & 2.7 \\
$U_{\text {max_scap }}$ & {$[\mathrm{V}]$} & 2.8 & 2.8 & 2.8 & 2.8 & 2.8 \\
$I_{\text {max_scap }}$ & {$[\mathrm{A}]$} & 105 & 110 & 115 & 125 & 150 \\
$m_{\text {scap }}$ & {$[\mathrm{g}]$} & 200 & 300 & 320 & 400 & 550 \\
$v_{\text {scap }}$ & {$\left[\mathrm{dm}^{3}\right]$} & 0.15 & 0.233 & 0.264 & 0.312 & 0.411 \\
$P_{\text {max_scap }}$ & {$\left[\mathrm{kW}^{3} \mathrm{~kg}^{-1}\right]$} & 11.4 & 10.5 & 12.1 & 13.0 & 11.4 \\
$W_{\text {max_scap }}$ & {$\left[\mathrm{Wh}^{-1} \mathrm{~kg}^{-1}\right]$} & 3.29 & 4.05 & 4.75 & 5.06 & 5.52 \\
& & & & & & \\
\hline \hline
\end{tabular}

${ }^{\mathrm{a} D a t a s h e e t s ~ f r o m ~ M a x w e l l ~}$ component libraries from suppliers and energetic requirements, represented by a load profile, which is a power profile. The sizing tool takes into account several constraints, such as electrical limits, which are reviewed in a second part. In the next stage, the sizing algorithm is described step by step, with a focus on setting parameters. Variables are discharge ratios for storage components, ambient temperature and cut-off frequency in relation with the energy management strategy. Finally, the optimization results are presented.

\section{A. Sizing tool inputs}

The sizing tool inputs are on one hand the energetic requirements that storage systems have to meet, and on the other hand characteristics of real components from supplier libraries.

\section{1) Energetic requirements for each system}

The energetic requirements are usually represented in the form of load profile (or power profile), such as defined in the previous paragraph. Afterwards, these requirements are shared out between both storage components with a low-pass filter to determine the specific requirements (energy and power) for each EESS. As seen in Fig. 3, the global required power is dispatched in four values for EESS, which are: useful energy

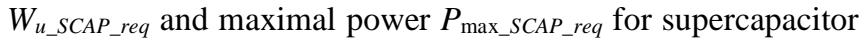
system, and useful energy $W_{u_{-} B A T_{-} r e q}$ and maximal power $P_{\text {max } \_B A T_{-} r e q}$ for secondary battery system. These values are input data for the sizing tool, and the cut-off frequency $f_{C 2}$ is a setting parameter.

\section{2) Database of storage cells}

The sizing of storage components is carried out by considering real cells, whose characteristics are based on simple models. For supercapacitor cells, the main characteristics are the capacitance $C_{\text {scap }}$ and the internal resistance $R_{\text {scap }}$, based on a standard model [18]. As for battery cells, their main characteristics are the capacity $C_{b a t}$, the OpenCircuit Voltage $E_{0 \_b a t}$ (which is in relation with the State-OfCharge $S O C$ ) and the internal resistance $R_{b a t}$, based on a quasistatic model, also called the Thevenin equivalent model [19]. The sizing tool is organized so as to review each cell from a database given in Table I for Maxwell supercapacitors and in Table II for Kokam batteries.

TABLE II

BATTERY CELL DATABASE FOR THE SYSTEM SIZING TOOL

\begin{tabular}{|c|c|c|c|c|c|c|c|}
\hline \multirow{2}{*}{$\frac{\text { Symbol }}{C_{b a t}}$} & \multirow{2}{*}{$\frac{\text { Unit }}{[\mathrm{Ah}]}$} & \multicolumn{6}{|c|}{ Values $^{\mathrm{a}}$} \\
\hline & & 0.8 & 2 & 4 & 4.8 & 8 & 16 \\
\hline$R_{b a t}$ & {$[\mathrm{~m} \Omega]$} & 12 & 8 & 12 & 20 & 4.5 & 2 \\
\hline$E_{0 \_b a t}$ & [V] & 3.7 & 3.7 & 3.7 & 3.7 & 3.7 & 3.7 \\
\hline$U_{\text {max_bat }}$ & [V] & 4.2 & 4.2 & 4.2 & 4.2 & 4.2 & 4.2 \\
\hline$I_{\max \_b a t}$ & [A] & 24 & 30 & 8 & 96 & 16 & 32 \\
\hline$M_{b a t}$ & {$[\mathrm{~g}]$} & 23 & 50 & 82 & 115 & 160 & 307 \\
\hline$v_{\text {bat }}$ & {$\left[\mathrm{cm}^{3}\right]$} & 13 & 29 & 41 & 65 & 80 & 167 \\
\hline$P_{\max \_b a t}$ & {$\left[\mathrm{~W} . \mathrm{g}^{-1}\right]$} & 4.38 & 2.52 & 0.41 & 3.51 & 0.42 & 0.44 \\
\hline$W_{\text {max_bat }}$ & {$\left[\mathrm{Wh} . \mathrm{kg}^{-1}\right]$} & 129 & 148 & 180 & 154 & 185 & 193 \\
\hline
\end{tabular}

${ }^{\mathrm{a}}$ Datasheets from Kokam 


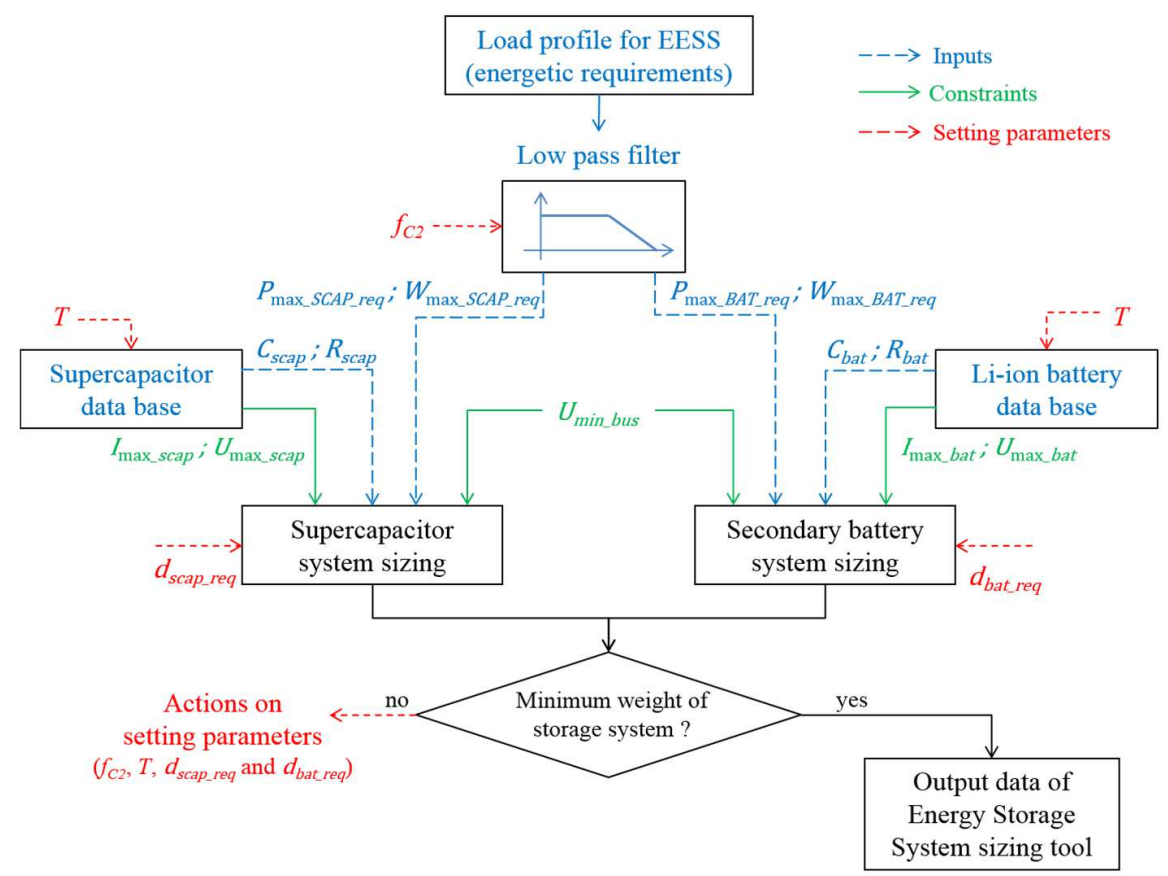

Fig. 4. Algorithm for Electrical Energy Storage Systems

\section{B. Constraints on the EESS sizing}

Storage components, included within a network, progress in an environment, which has to be taken into account as a constraint for their sizing.

\section{1) Technological limits of components}

The first constraints for storage systems are electrical ones, which are their own technological limits such as the maximal current ( $I_{\text {max_scap }}$ and $I_{\text {max_bat }}$ ) acceptable by cells and the minimum and maximum cell voltages $\left(U_{\text {max }_{\_} \text {scap }}, U_{\text {min_scap }}\right.$, $U_{\text {max_bat }}$ and $\left.U_{\text {min_bat }}\right)$. Their values are given for each cell by manufacturers in Table I and Table II.

\section{2) Environment influence}

The second electrical constraint is due to the EESS integration in a network. In fact, the storage system voltage is in relation with the network voltage $U_{b u s}$, even if there are converters to connect storage systems to DC bus (Fig. 2). In our application, as considered choppers are boost-converters, the EESS maximal voltage must be lower than the minimal DC network voltage $U_{\text {min_bus }}$, as described in (1) and in (2).

$$
\begin{gathered}
U_{S C A P} \leq U_{\text {min_bus }} \\
U_{B A T} \leq U_{\text {min_bus }}
\end{gathered}
$$

where $U_{S C A P}$ is the supercapacitor bank voltage and $U_{B A T}$ is the battery system voltage.

Another kind of environment constraint can be the ambient temperature. In fact, it has a significant influence on storage system performances. However, temperature is not considered as a constraint in this study, but as a setting parameter of the sizing tool, so as to observe its impact on sizing results.

\section{3) Temperature influence on cell parameters}

In previous studies [12], [13], the temperature influence on the storage device parameters was determined and is expressed by (3) for supercapacitor resistance and by (4) and (5) for battery resistance and capacity. The impact of temperature on the supercapacitor capacitance is neglected.

$$
\begin{aligned}
& R_{\text {scap }}(T)=\left(0.0001 \cdot T^{2}-0.0097 \cdot T+1.157\right) R_{\text {scap } @ 25^{\circ} \mathrm{C}} \\
& R_{\text {bat }}(T)=\left(0.0009 \cdot T^{2}-0.078 \cdot T+2.183\right) R_{\text {bat } @ 25^{\circ} \mathrm{C}} \\
& C_{\text {bat }}(T)=(0.0015 \cdot T+0.967) C_{\text {bat } @ 25^{\circ} \mathrm{C}}
\end{aligned}
$$

where $R_{\text {scap } @ 25^{\circ} \mathrm{C}}, R_{b a t} @ 25^{\circ} \mathrm{C}$ and $C_{b a t} @ 25^{\circ} \mathrm{C}$ are the nominal values for resistances and capacity at $25^{\circ} \mathrm{C}$.

\section{Method for supercapacitor bank and battery sizing}

The sizing method for both storage systems is detailed below, step by step.

First, the maximal energy is determined from the useful energy, by taking into account the discharge ratio or the depthof-discharge for each source. For battery system, the depth-ofdischarge $d_{\text {batreq }}$ expresses the relation between the useful energy and the maximal stored energy. For supercapacitor system, the discharge ratio $d_{\text {scap_req, }}$ expressed in (6), is a voltage ratio.

$$
\begin{aligned}
& d_{\text {scap_req }}=U_{\text {scap }} / U_{\text {scap_max }} \\
& W_{\text {max } \_S C A P \_r e q}=W_{u_{-} S C A P_{-} r e q} /\left(1-d_{\text {scap_req }}{ }^{2}\right) \\
& W_{\text {max } \_B A T_{\_} r e q}=W_{u_{-} B A T_{-} r e q} / d_{\text {bat_req }}
\end{aligned}
$$

where $W_{\text {max }}$ SCAP_req is the maximal energy for supercapacitor

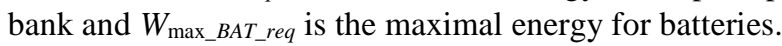


The second step consists in determining the cell number necessary to provide the required maximal energy.

$$
\begin{gathered}
N_{\text {scap_req }}=\frac{2 \cdot W_{u_{\_} S C A P_{-} r e q}}{\left(1-d_{\text {scap_req }}{ }^{2}\right) \cdot C_{\text {scap }} \cdot U_{\max \_s c a p^{2}}} \\
N_{\text {bat_req }}=\frac{W_{u_{\_} B A T_{-} r e q}}{d_{\text {bat_req }} \cdot C_{\text {bat }} \cdot U_{\text {max } \_b a t}}
\end{gathered}
$$

where $N_{\text {scap_req }}$ is the necessary cell number for supercapacitor bank and $N_{\text {bat_req }}$ is the necessary cell number for batteries.

In the next step, the maximal required current for a cell is determined from power expression.

$$
\begin{aligned}
& I_{\text {max_scap_req }}=\frac{U_{\text {scap }}}{2 . R_{\text {scap }}}- \\
& \frac{\sqrt{\left(N_{\text {scap_req }} \cdot U_{\text {Scap }}\right)^{2}-4 . N_{\text {scap_req }} \cdot R_{\text {Scap }} \cdot P_{\max \_S C A P_{-} r e q}}}{2 \cdot N_{\text {Scap_req }} \cdot R_{\text {Scap }}} \\
& I_{\text {max }_{\text {bat_req }}}=\frac{E_{0 \_ \text {bat }}}{2 \cdot R_{\text {bat }}}- \\
& \underline{\left.\sqrt{\left(N_{\text {bat_req }} \cdot E_{0} \_\right. \text {bat }}\right)^{2}-4 \cdot N_{\text {bat_req }} \cdot R_{\text {bat }} \cdot P_{\max \_B A T_{\_} r e q}} \\
& \text { 2.N } N_{\text {bat_req. }} \cdot R_{\text {bat }}
\end{aligned}
$$

where $I_{\text {max_scap_req }}$ is the maximal required current for a supercapacitor cell and $I_{\text {max_bat_req }}$ is the maximal required current for a battery cell.

The last step concerns the determination of the numbers of cells in serial and in parallel while considering the maximal required current and the maximal current acceptable by one cell. In the case where the maximal required current is lower than the maximal current acceptable by one cell, the cell numbers in serial are determined from the network voltage requirement and the cell numbers in parallel are deduced from the required cell numbers. The cell numbers in serial, $N_{s_{-} \text {scap }}$ and $N_{S_{s} b a t}$, are determined to respect this requirement and must be integers, as expressed in (13) and (14).

$$
\begin{aligned}
& N_{S_{s} \text { scap }}=\left\lfloor U_{\min \_b u s} / U_{\max _{\text {_scap }}}\right\rfloor \\
& N_{S_{-} b a t}=\left\lfloor U_{\min \_b u s} / U_{\text {max } \_b a t}\right\rfloor
\end{aligned}
$$

The cell numbers in parallel, $N_{p_{-} s c a p}$ and $N_{p_{-} b a t}$, should comply with both the energetic requirement and the current limit. The cell number in parallel for the supercapacitor bank is:

$N_{p_{-} \text {scap }}=\left\lceil\max \left(\alpha_{\text {scap }}, \beta_{\text {scap }}\right)\right\rceil$

with:

$\alpha_{\text {scap }}=\frac{2 \cdot W_{u_{\_} S C A P_{\_} r e q}}{\left(1-d_{\text {scap_req }}{ }^{2}\right) \cdot C_{\text {scap }} \cdot U_{\text {max } \_s c a p} \cdot U_{\min \_b u s}}$

$\beta_{\text {scap }}=\frac{U_{\text {scap }}}{2 . R_{\text {scap }} \cdot I_{\text {max } \_ \text {scap }}}-$

$\sqrt{\left(N_{\text {scap_req }} \cdot U_{\text {scap }}\right)^{2}-4 \cdot N_{\text {scap_req }} \cdot R_{\text {Scap }} \cdot P_{\max \_S C A P_{-} \text {req }}}$

$2 . N_{\text {scap }}$ req $\cdot R_{\text {scap }} \cdot I_{\max }$ sca

The cell number in parallel for secondary battery system is:

$N_{p_{-} b a t}=\left\lceil\max \left(\alpha_{\text {bat }}, \beta_{\text {bat }}\right)\right\rceil$

with:

$\alpha_{\text {bat }}=\frac{W_{u_{\_} B A T_{-} r e q}}{d_{\text {bat_req }} \cdot C_{\text {bat }} \cdot U_{\text {min } \_ \text {bus }}}$

$\beta_{\text {bat }}=\frac{E_{0 \_b a t}}{2 \cdot R_{\text {bat }} \cdot I_{\text {max } \_b a t}}-$

$\sqrt{\left(N_{\text {bat_req }} \cdot E_{0_{-}} \text {bat }\right)^{2}-4 \cdot N_{\text {bat_req }} \cdot R_{\text {bat }} \cdot P_{\text {max }_{-} B A T_{-} r e q}}$

2.N $N_{\text {bat_req }} \cdot R_{\text {bat }} \cdot I_{\text {max_bat }}$

\section{Optimization algorithm}

In this part, the optimization criterion is specified, the parameters are highlighted and the algorithm is detailed. In an aircraft, the objective is to embed storage systems that have the best performances for a minimal weight, which means the best specific energy and power. Therefore, the global storage system weight is chosen to be minimized as a critical one, even if other criteria could have been considered as cost [2-4], [15] or fuel consumption [3], [20], [21] for other applications.

1) Expression of the global system weight

For the supercapacitor system, the total weight $M_{S C A P}$ is given in (21) and the battery system's one $M_{B A T}$ is given in (22). Therefore, the global weight of the storage system $M_{s y s}$ equals the addition of (21) and (22).

$$
\begin{aligned}
& M_{S C A P}=N_{s_{-} \text {scap }} \cdot N_{p_{-} \text {scap }} \cdot m_{\text {scap }} \\
& M_{\text {BAT }}=N_{S_{-} \text {bat }} \cdot N_{p_{-} \text {bat }} \cdot m_{\text {bat }}
\end{aligned}
$$

where $m_{\text {scap }}$ is the weight of a supercapacitor cell and $m_{\text {bat }}$ is the weight of a battery cell.

According to the previous formulas, the total weights for supercapacitor and battery systems can be expressed in the form of 6-variable functions:

$M_{S C A P}=$

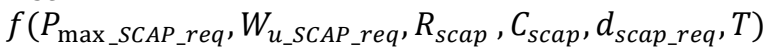

$M_{B A T}=$

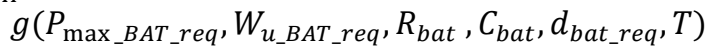

\section{2) Setting parameters}

As seen in previous paragraphs, the first setting parameter of the sizing tool is the cut-off frequency of the low-pass filter. Indeed, the first stage of the algorithm described in Fig. 4 consists in computing the required maximal power and useful energy for supercapacitor and battery systems according to the cut-off frequency value. This step is carried out with a MatlabSimulink $^{\circledR}$ scheme, and the cut-off frequency is within the range from $0.1 \mathrm{mHz}$ to $0.1 \mathrm{~Hz}$ with an increment of $0.1 \mathrm{mHz}$. This frequency range is determined by considering the frequency characteristics of the storage systems, as they are able to provide power during a time between a few seconds and a few hours. Another setting parameter is temperature. Its influence on cell parameters is taken into account in the algorithm described in Fig. 4, according to relations (3), (4) and (5). In this study, the ambient temperature can vary from $-25^{\circ} \mathrm{C}$ to $+55^{\circ} \mathrm{C}$. As the considered mission stage is the starting time, storage components have the same initial temperature as their environment's one. The last setting parameter is the discharge ratio or depth-of-discharge for each storage system. These values are expressed in (6) and (8) and can be different for supercapacitor and battery systems. In this study, the battery depth-of-discharge can vary between $10 \%$ and $75 \%$. Thus, its discharge ratio range is $[0.1 ; 0.75]$. As for the supercapacitor system, its useful energy can vary between $19 \%$ and $75 \%$. Thus, its discharge ratio range is $[0.5 ; 0.9]$. The maximum ratio is limited to $75 \%$ to keep an energy reserve in storage devices to face possible failure or disoperation. 


\section{3) Optimization algorithm}

A configuration $i$ is given by the type of supercapacitor cell and the type of battery cell. Each alternative configuration is examined and the values $\left(f_{C 2} ; d_{\text {scap_req }} ; d_{\text {bat_req }} ; T\right)$ are determined so as to minimize the weight of the system for the configuration $i$. This problem can be mathematically formulated as an optimization problem:

$$
M_{\text {sys }}(i)=
$$

$\operatorname{Min}_{f_{C 2}, d_{\text {scap_req }}, d_{\text {bat_req }, T}}\left[M_{\text {SCAP }}\left(\boldsymbol{f}_{C 2}, R_{\text {scap }}(i), C_{\text {scap }}(i), \boldsymbol{d}_{\text {scap_req }}, \boldsymbol{T}\right)+\right.$ $\left.M_{B A T}\left(\boldsymbol{f}_{C 2}, R_{\text {bat }}(i), C_{\text {bat }}(i), \boldsymbol{d}_{\text {bat_req }}, \boldsymbol{T}\right)\right]$

The internal resistance and the capacitance of the supercapacitor cell for the configuration $i$ are denoted by $R_{\text {scap }}(i)$ and $C_{\text {scap }}(i)$. The internal resistance and the capacity of the battery cell for the same configuration are denoted by $R_{b a t}(i)$ and $C_{b a t}(i)$. The minimal weight of the system obtained for this configuration is denoted by $M_{s y s}(i)$. This optimization problem is solved with the simulated annealing method implemented in the Matlab function SIMULANNEALBND of the Global Optimization Tool-box. This minimal weight is computed for each configuration. Then, the best one (denoted by $i_{\text {best }}$ ), which has the minimal weight among all possible configurations, is selected. The type of cells for supercapacitor $\left(R_{\text {scap }}\left(i_{\text {best }}\right)\right.$ and $\left.C_{\text {scap }}\left(i_{\text {best }}\right)\right)$ and battery $\left(R_{\text {scap }}\left(i_{\text {best }}\right)\right.$ and $\left.C_{\text {bat }}\left(i_{\text {best }}\right)\right)$, their discharge ratios $\left(d_{\text {scap_req }}\right.$ and $\left.d_{\text {bat_req }}\right)$, their cell numbers in parallel $\left(N_{p_{\_} s c a p}, N_{p_{-} b a t}\right)$, and in serial $\left(N_{s_{-} s c a p}\right.$, $\left.N_{s_{-} b a t}\right)$, the temperature and the cut-off frequency are determined in this way. The function (the weight of the system for a given configuration) seems to have many local minima. As the simulated annealing algorithm performs a wide random search, the chance of being trapped in a local minimum is decreased. The simulated annealing is a nondeterministic algorithm, which means that running the method many times may give different results. In our experimentations, to avoid the convergence to a local minimum, we run 100 times the simulated annealing method with random starting points. We specify the bounds of each variable $\left(f_{C 2} ; d_{\text {scap_req }} ; d_{\text {bat_req }} ; T\right)$. The usual parameters are set to default values in the Matlab function: the maximal number of iterations ("MaxIter" equals $+\infty)$; the maximal number of function evaluation ("MaxFunEval" equals 3,000 times the number of variables); the initial temperature of the cooling system is set to 100 . The Matlab function keeps track of the average change in the function value for "StalliterLimit" (here, set to 100) iterations. If the average change is smaller than the function tolerance "TolFun" (set to $10^{-6}$ ), then the algorithm will stop. For this study, we first concentrate on the model formulation. The setting parameters of the simulated annealing method or the use of another optimization algorithm is not the main core of our problem so far as the optimization problem is easily solvable. Moreover it is a sizing problem and not a real-time problem. Experiments show that the simulated annealing method rarely remains stuck in a local minimum. Indeed, the algorithm accepts all new points that lower the objective (in case of minimization), but also, with a certain probability, points that raise the objective. By accepting these points, the algorithm avoids being trapped in local minima in early iterations and is able to explore globally for better solutions.
Further research efforts should focus on computational efficiency for the function evaluation which is a time consuming part of the algorithm.

\section{E. Sizing tool outputs}

The output data of the sizing tool are these results: the most appropriate cell for each Electrical Energy Storage System, the cell numbers and their serial or parallel association $\left(N_{s_{-} s c a p}\right.$, $\left.N_{p_{-} \text {scap }}, N_{s_{-} b a t}, N_{p_{-} \text {bat }}\right)$, the energetic performances of each EESS $\left(W_{S C A P}, P_{\text {max } \_S C A P}, W_{B A T}, P_{\max _{-} B A T}\right)$ and their electrical and mechanical characteristics: storage capacity $\left(C_{S C A P}, C_{B A T}\right)$, internal resistance $\left(R_{S C A P}, R_{B A T}\right)$, weight $\left(M_{S C A P}, M_{B A T}\right)$, volume $\left(v_{S C A P}, v_{B A T}\right)$. System volumes are given for information. The sizing tool also gives the configuration $\left(f_{C 2} ; d_{\text {scap_req }} ; d_{\text {bat_req }} ; T\right)$ which leads to reach the minimum weight.

\section{ASSESSMENT OF THE SIZING RESULTS}

In this part, the results of the sizing are presented and the sizing validity is assessed on the whole temperature range according to two criteria.

\section{A. Sizing results}

As explained before, the function (the weight of the system for a given configuration) has many local minima. Therefore, the sizing tool gives a few solutions. The two best solutions, which correspond to two weights, are reviewed. The first solution leads to a minimum weight of $24.1 \mathrm{~kg}$ and the second one leads to a weight of $26.1 \mathrm{~kg}$.

The first solution is obtained with a combination of $650 \mathrm{~F}$ and 4.8A.h cells and with the following configuration: the cutoff frequency is $8.5 \mathrm{mHz}$, discharge ratios are for supercapacitors: 0.54 and for batteries: 0.74 (that means the supercapacitor system depth-of-discharge is $71 \%$ and the battery system's one is $74 \%$ ), and temperature is $7^{\circ} \mathrm{C}$.

The second solution results from a combination of $650 \mathrm{~F}$ and 2A.h cells and from this configuration: the cut-off frequency is $0.05 \mathrm{~Hz}$, discharge ratios are for supercapacitors: 0.90 and for batteries: 0.74 (that means the supercapacitor system is used at $19 \%$ and the battery system at $74 \%$ ), and the ambient temperature is: $-24.8^{\circ} \mathrm{C}$.

In a previous work [5], where the algorithm was sequential and where the ambient temperature was set at $25^{\circ} \mathrm{C}$, the minimal weight was obtained in the following configuration: the cut-off frequency was $5 \mathrm{mHz}$, the discharge ratio was 0.5 for the supercapacitor system and the depth-of-discharge was $75 \%$ for the battery system. This configuration, close to the first solution's one, led to a weight of $41 \mathrm{~kg}$. The analysis of the weight distribution between both storage systems showed that the supercapacitor system had a dominating weight. To compare, the previous supercapacitor system is twice as weighty as the one given by the optimized sizing tool described in this paper. This comparison shows the interest of optimizing the sizing by acting on variables such as the cut-off frequency, discharge ratios and the ambient temperature. 


\section{B. Validation of the sizing results}

First, the method to assess the sizing results on the whole temperature range is detailed and then, validation is carried out according to system voltages and states-of-charge.

\section{1) Assessment method}

To check the sizing results, the behavior of the sized EESS is simulated in response to the typical load profile for a starting phase. A model of the global system is implemented, including the simple models of the identified cells, in a Matlab $^{\circledR}$ Simulink file (Fig. 5). As these models were defined from characterization tests at different temperatures [12], [13], simulations are carried out on the whole range of temperatures $\left[-25^{\circ} \mathrm{C} ;+55^{\circ} \mathrm{C}\right]$. The assessment criteria can be the storage component voltages or states-of-charge.

\section{2) Sizing validation according to the system voltages}

On the one hand, the simulation results are given for the storage systems, as defined in the first solution (which leads to a weight of $24.1 \mathrm{~kg}$ ). In Fig. 6 and Fig. 7, the supercapacitor and battery system voltages are plotted as a function of time (over the load profile duration) and temperature. Storage systems are initially charged, thus their voltage begins at 1 (per unit). The voltage evolution is in good agreement with the load profile's one, and the influence of temperature is

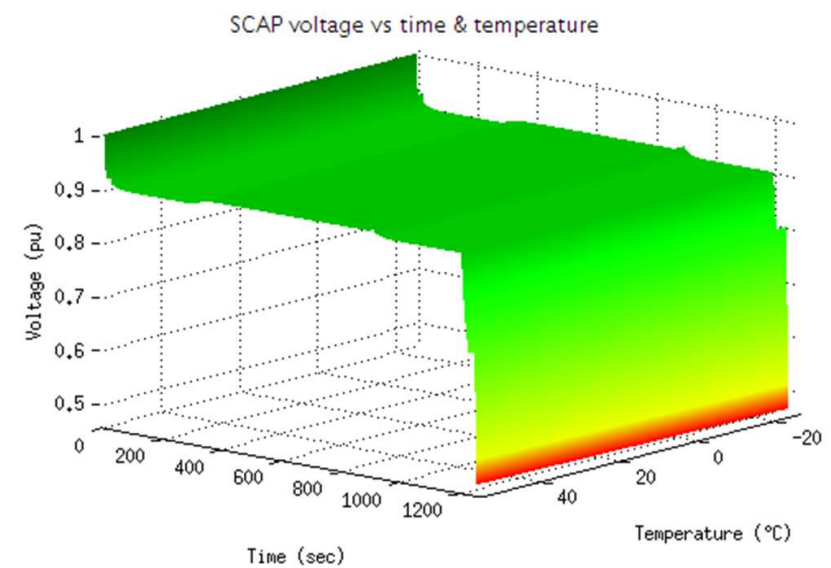

Fig. 6. Supercapacitor system voltage vs. time and temperature, for the first solution

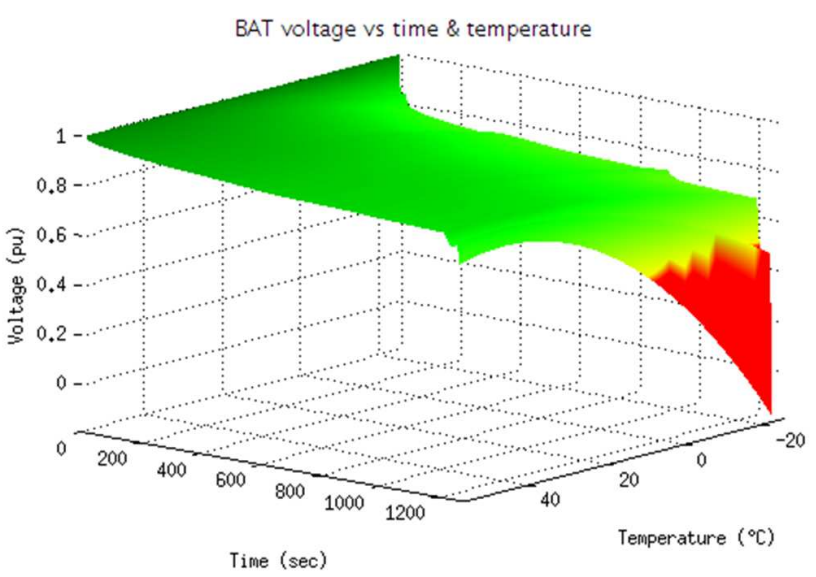

Fig. 7. Battery system voltage vs. time and temperature, for the first solution

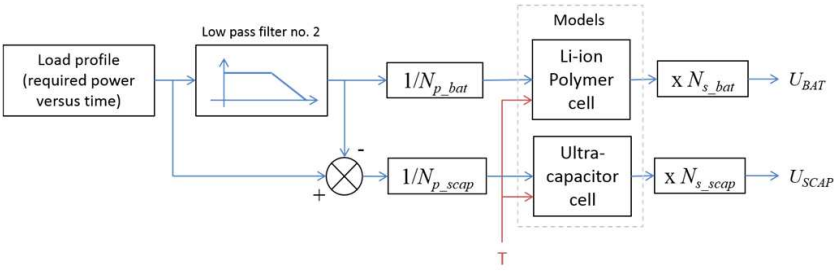

Fig. 5. Validation of Electrical Energy Storage System sizing by simulation

particularly observable on the battery system voltage plot. The red part of the area indicates a system voltage lower than 0.5 p.u., considered as the minimum acceptable value, in relation with the boost-converter conversion ratio. As the results obtained with this first solution are not completely satisfactory, the second sizing result is also assessed.

On the second hand, the simulation results are given for the supercapacitor and battery systems, as defined in the second solution (which leads to a weight of $26.1 \mathrm{~kg}$ ). In Fig. 8 and Fig. 9, the storage system voltages are plotted as a function of time and temperature. For this second solution, the EESS voltage requirement (upper than 0.5 p.u.) is fulfilled over the mission profile, whatever the temperature is. Eventually, both energetic requirements and environmental constraints are satisfied by this second solution. According to the voltage criterion, the second solution is taken on for the next validation step.

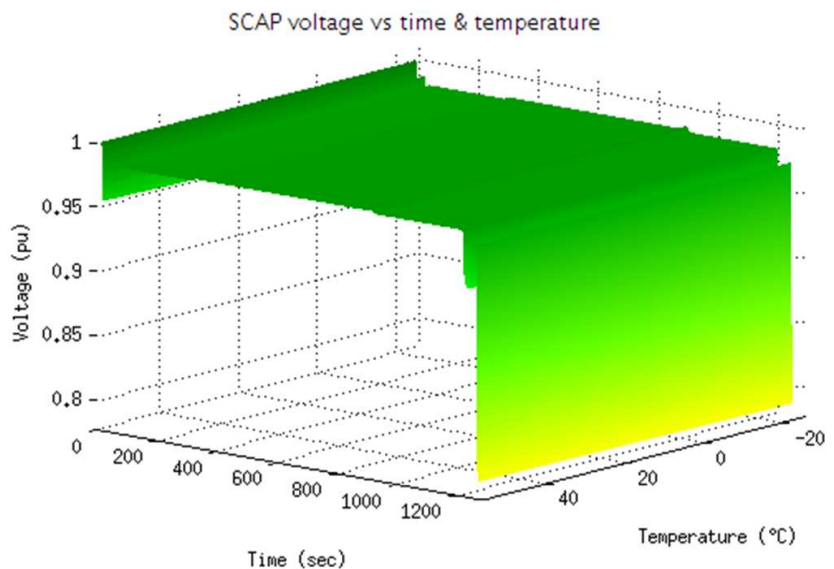

Fig. 8. Supercapacitor system voltage vs. time and temperature, for the second solution

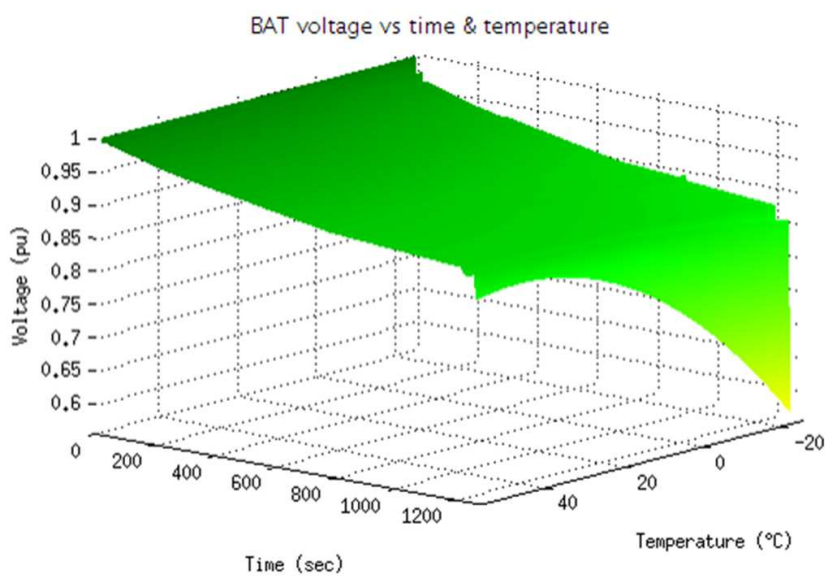

Fig. 9. Battery system voltage vs. time and temperature, for the 2 nd solution 
3) Sizing validation according to the system states-of-charge

For the storage system defined as the second solution, states-of-charge (SoC) are plotted as a function of time (over the profile duration) and temperature in Fig. 10 and Fig. 11. In these plots, different points are highlighted.

First, storage systems are initially charged, thus their stateof-charge begins at 1 (or 100\%).

Secondly, the SoC evolution is in good agreement with the load profile's one: EESS state-of-charge is overall decreasing because they are only discharged and they do not recover any power during this starting phase. At the end of the mission profile, both storage system states-of-charge are higher than $25 \%$. As a reminder, this minimum SoC level was set so as to keep enough energy to face possible failure.

Thirdly, the influence of temperature is observable on the battery system SoC plot. Nevertheless, whatever the temperature is, the battery state-of-charge remains higher than $25 \%$. As for the supercapacitor system, the temperature has no impact on its SoC.

Finally, sizing results are validated according to the "stateof-charge" criterion on the whole temperature range.

\section{ANALYSIS OF THE SIZING RESULTS}

In a first part, an analysis is suggested in order to underline the influence of the cut-off frequency, the discharge ratios and the ambient temperature on the global storage system weight. In a second part, an adaptation of the energy management strategy is carried out so as to preserve the battery, whose performances are degraded at low temperatures.

\section{A. Influence of the setting parameters on the system weight}

This analysis consists in plotting the evolution of the global system weight according to the identified setting parameters. It is also a way to check if there are many local minima in the function $M_{s y s}$, sum of $M_{S C A P}$ and $M_{B A T}$ as expressed respectively by (23) and (24).

Firstly, it is interesting to plot the evolution of the global storage system weight according to these setting parameters: temperature and cut-off frequency. In this case, discharge ratios are constant and set at their maximum values: 0.5 for the supercapacitor system and 0.75 for the battery system. Fig. 12 shows there is a minimum area where the global weight is around $25 \mathrm{~kg}$, in agreement with the results given in the previous paragraph.

Secondly, the evolution of the supercapacitor and battery system weights as functions of the cut-off frequency and their discharge ratio are given respectively in Fig. 13 and Fig. 14. In this case, the temperature is set at one specified value, as for example at $25^{\circ} \mathrm{C}$. The lower the cut-off frequency is, the lighter the battery system is, but the heavier the supercapacitor system is. Therefore, the optimization algorithm must find the best compromise between both weights.

This analysis highlights the necessity to optimize the global system weight because the minimum weight does not correspond to the sum of the minima of both storage system.

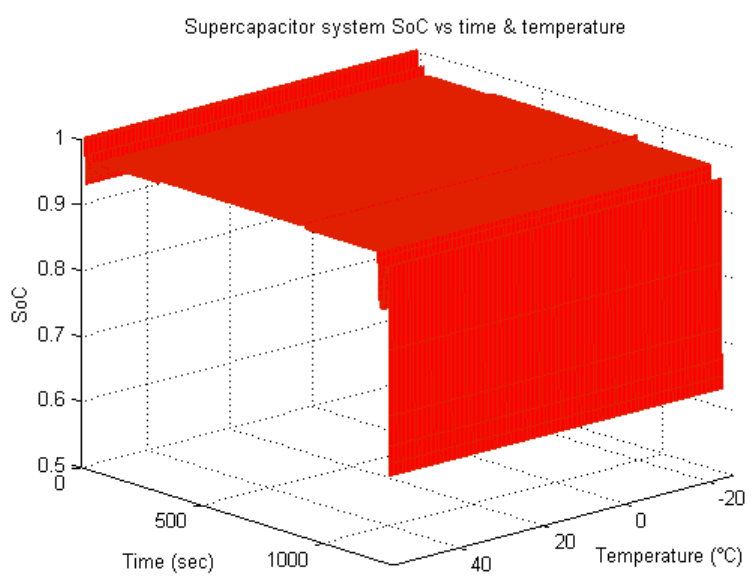

Fig. 10. Evolution of supercapacitor system SoC vs. time and temperature, for the second solution

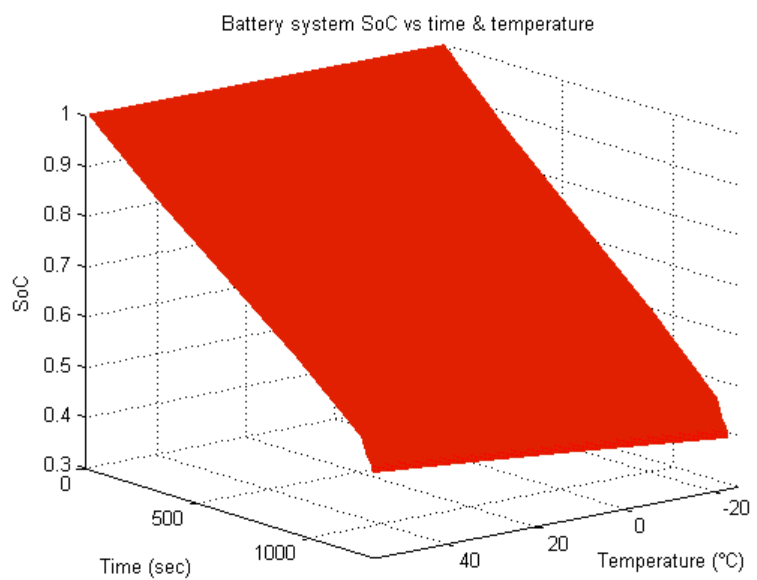

Fig. 11. Evolution of battery system SoC vs. time and temperature, for the second solution

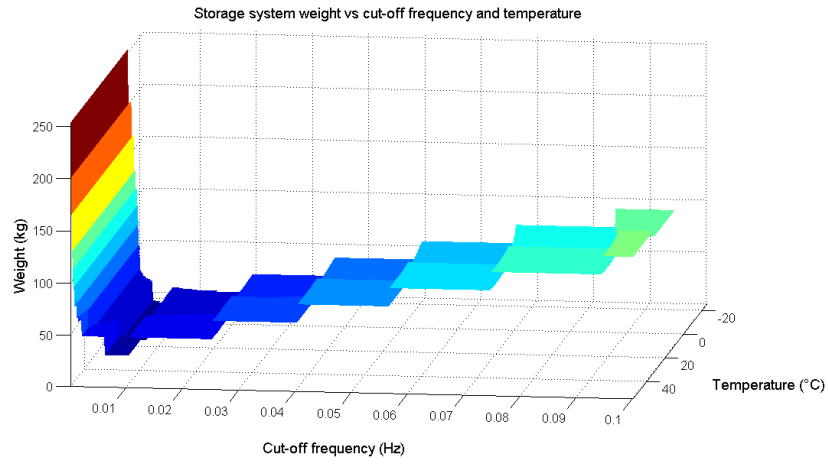

Fig. 12. Global system weight vs. cut-off frequency and temperature, with constant discharge ratios

\section{B. Adaptation of the energy management}

Sizing results given in the previous chapter underlined the degradation of battery performances at low temperatures. To avoid premature ageing of the battery system, it could be relevant to study a strategy to adapt the energy management according to the ambient temperature. 
As seen in Fig. 11, the battery SoC is lower than $40 \%$ when the temperature is lower than $-20^{\circ} \mathrm{C}$. To protect batteries on this specific temperature range, energy management (through the cut-off frequency) can be adapted to avoid a too low SoC [22]. Then, the cut-off frequency is determined so as to maintain the battery SoC at $40 \%$, on the range: $\left[-25^{\circ} \mathrm{C}\right.$; $20^{\circ} \mathrm{C}$ ]. Its evolution on this temperature range is expressed in (26), where $f_{C 2 \_}$is the cut-off frequency determined by the sizing tool, which stays valid on the range: $\left.]-20^{\circ} \mathrm{C} ;+55^{\circ} \mathrm{C}\right]$.

$$
f_{C 2}(T)=\left(0.0026 \cdot T^{2}+0.183 \cdot T+3.65\right) f_{C 2 \_}
$$

The evolution of the battery SoC, without and then with the adaptation of the energy management, is given in Fig. 15 on the last seconds of the mission profile. Adapting the energy management allows one to maintain a battery state-of-charge which is acceptable. The supercapacitor system provides the necessary energy to preserve the battery system at low temperatures.

\section{CONCLUSION}

In More Electric Aircraft (MEA), the electrification of embedded network leads to the addition of new Electrical Energy Storage Systems (EESS). Their sizing is a critical issue and its optimization is mandatory to implement storage systems in some aircrafts.

In this paper, a sizing tool based on the simulated annealing method is presented to minimize the global storage system weight, which is an essential requirement in aeronautics.

This sizing tool includes different inputs, constraints and parameters, which are summed up below. First, a load profile and the energy management to share it out between both storage systems are used in the first part of the sizing tool. Indeed, the load profile represents the power requirements and is a sizing tool input. The energy management introduces a setting parameter for the sizing tool: the cut-off frequency of the low-pass filter. Then, the databases of storage cells from suppliers are integrated in the sizing tool and are also considered as inputs. The technological limits (maximum current and voltage) for each cell are some of constraints for the sizing tool. On the other hand, the characteristics of the simple models take into account the impact of temperature, which can be considered as a constraint or as a setting parameter. Finally, the electrical architecture, where the storage systems are implemented, is taken into account. This requires a voltage for storage device which is in relation with the network voltage and with the characteristics of the converters associated to the storage components. Hence, bus voltage is considered as a constraint and the discharge ratios (voltage ratio or depth-of-discharge) as setting parameters for the sizing tool.

The optimal sizing results in a cell combination (batteries and supercapacitors) and in parameter configuration. Two solutions are reviewed and their validity is assessed on the whole temperature range, according to two criteria: system voltages and states-of-charge. Finally, for the best solution, an

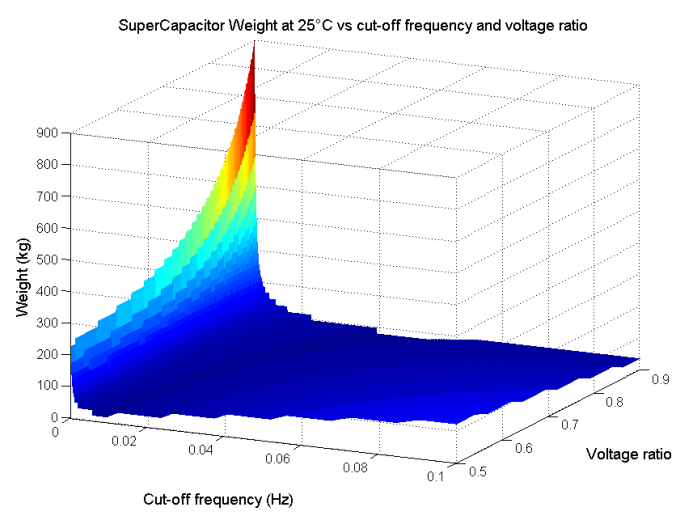

Fig. 13. Supercapacitor system weight vs. cut-off frequency and voltage ratio, at $25^{\circ} \mathrm{C}$

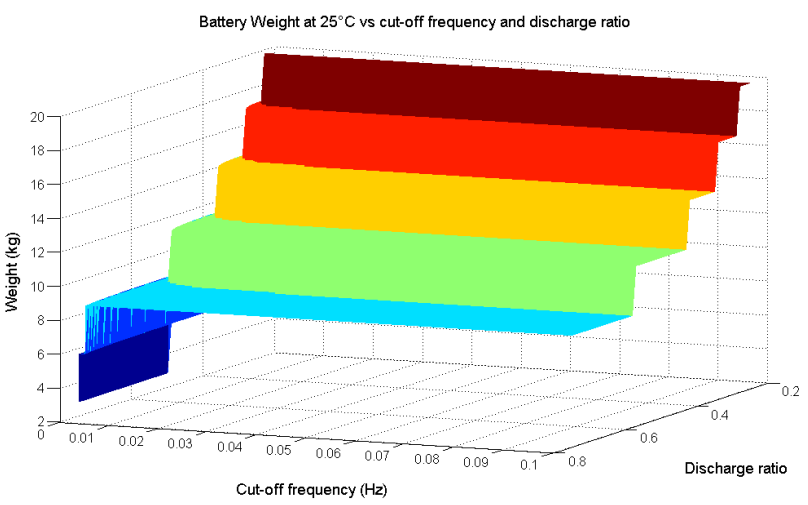

Fig. 14. Battery system weight vs. cut-off frequency and discharge ratio, at $25^{\circ} \mathrm{C}$
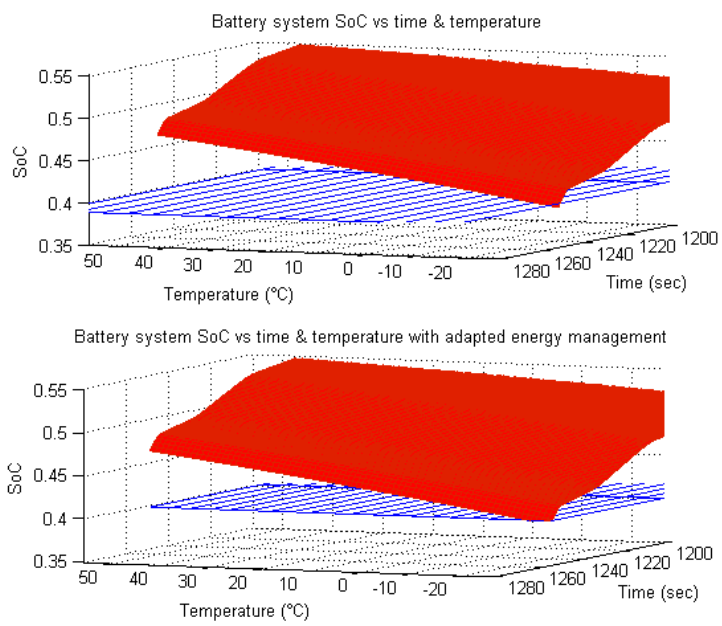

Fig. 15. Evolution of battery system SoC vs.time and temperature, without and with adapted energy management

adaptation of the energy management strategy is suggested to preserve battery, whose performances are degraded at low temperature.

Further work will explore the optimal sizing of storage systems and their converters to minimize the weight of the whole electrical power chains. 


\section{ACKNOWLEDGMENT}

This study has been carried out within the framework of a research program, funded by Region de Franche-Comté and partially funded by the Labex ACTION program (contract ANR-11-LABX-01-01).

\section{REFERENCES}

[1] X. Roboam, "New trends and challenges of electrical networks embedded in "more electrical aircraft", IEEE International Symposium on Industrial Electronics (ISIE), pp. 26-31, 2011.

[2] A. Ostadi, M. Kazerani, "Optimal sizing of the battery unit in a plug-in electric vehicle”, IEEE Transactions on Vehicular Technology, vol. 63, no. 7, pp. 3077-3084, 2014.

[3] E. Tara, S. Shahidinejad, S. Filizadeh, E. Bibeau, "Battery storage sizing in a retrofitted plug-in hybrid electric vehicle", IEEE Transactions on Vehicular Technology, vol. 59, no. 6, pp. 2786-2794, 2010.

[4] R. E. Araujo, R. de Castro, C. Pinto, P. Melo, D. Freitas, "Combined sizing and energy management in EVs with batteries and supercapacitors", IEEE Transactions on Vehicular Technology, vol. 63 no. 7, pp. 3062-3076, 2014.

[5] N. Devillers, M. C. Péra, D. Bienaimé, M.-L. Grojo, "Influence of the energy management on the sizing of Electrical Energy Storage Systems", Journal of Power Sources, vol. 270, pp. 391-402, 2014.

[6] F. Lacressonnière, E. Bru, G. Fontes, X. Roboam, "Experimental validation of a hybrid emergency network with low and medium voltage Li-ion batteries for more electrical aircraft", $15^{\text {th }}$ European Conference on Power Electronics and Applications (EPE), Lille, September 2013.

[7] X. Roboam, O. Langlois, H. Piquet, B. Morin, C. Turpin, "Hybrid power generation system for aircraft electrical emergency network", IET Electrical Systems in Transportation, vol. 1, no. 4, pp. 148-155, 2011.

[8] C. Pan, L. Chen, L. Chen, C. Huang M. Xie, "Research on energy management of dual energy storage system based on the simulation of urban driving schedules", Electrical Power and Energy Systems, vol. 44, pp. 37-42, 2013.

[9] S. Vazquez, S. M. Lukic, E. Galvan, L. G. Franquelo, J. M. Carrasco, "Energy storage systems for transport and grid applications", IEEE Transactions on Industrial Electronics, vol. 57, no. 12, pp. 3881-3895, 2010
[10] H. Ibrahim, A. Ilinca, J. Perron, "Energy storage systems Characteristics and comparisons", Renewable and sustainable energy reviews, vol. 12, pp. 1221-1250, 2008.

[11] P. Hall, E. Bain, "Energy storage technologies and electricity generation", Energy Policy, vol. 36, pp. 4352-4355, 2008.

[12] N. Devillers, S. Jemei, M. Péra, D. Bienaimé, F. Gustin, "Review of characterization methods for supercapacitor modelling", Journal of Power Sources, vol. 246, pp. 596-608, 2014.

[13] N. Devillers, M.-C. Péra, S. Jemei, F. Gustin, D. Bienaimé, "Complementary characterization methods for Lithium-ion Polymer secondary battery modeling”, Electrical Power and Energy Systems, vol. 67, pp. 168-178, 2015.

[14] EN2282, "Aerospace series - Characteristics of aircraft electrical supplies", Bureau de Normalisation de l'Aéronautique et de l'Espace, 1992.

[15] F. Baalbergen, P. Bauer and J. Ferreira, "Energy storage and power management for typical 4Q-load", IEEE Transactions on Industrial Electronics, vol. 56, pp. 1485-1498, 2009.

[16] G. Souffran, L. Miègeville, P. Guérin, "Simulation of real-world vehicle missions using a stochastic Markov model for optimal powertrain sizing”, IEEE Transactions on Vehicular Technology, vol. 61, no. 8, pp. 3454-3465, 2012.

[17] D. Bienaimé, N. Devillers, M. Péra, F. Gustin, A. Berthon, M-L. Grojo, "Energetic Macroscopic Representation as an efficient tool energy management in a hybrid electrical system embedded in a helicopter", Conference on Electrical Systems for Aircraft, Railway and Ship propulsion (ESARS), Bologna, 2012.

[18] IEC62391-1, "Fixed electric double-layer capacitors for use in electronic equipement - Part 1: Generic specification", International Electrotechnical Commission, 2005.

[19] L. Thévenin, "Extension of Ohm's law to complex electromotive circuits", Annales Télégraphiques, vol. 10, pp. 222-224, 1883.

[20] R. Doucette, M. McCulloch, "A comparison of high-speed flywheels, batteries and ultracapacitors on the bases of cost and fuel economy as the energy storage system in a fuel cell based hybrid electric vehicle", Journal of Power Sources, vol. 196, pp. 1163-1170, 2011.

[21] L. Wang, E. G. Collins, H. Li, "Optimal design and real-time control for energy management in electric vehicles", IEEE Transactions on Vehicular Technology, vol. 60, no. 4, pp. 1419-1429, 2011.

[22] P. Saenger, N. Devillers, K. Deschinkel, M-C. Péra, “An optimal sizing of electrical energy storage system for an accurate energy management in an aircraft", Vehicle Power and Propulsion Conference (VPPC), October 19-22, Montréal (QC), Canada, 2015. 